\title{
Variable Frequency Drive Importance in an LPG Plant: Case Study
}

\section{Salem Hebri*}

Research and Technology Division, SONATRACH, BP 74-31230 SONATRACH Village Nº6, Aïn El Bia, Algeria

\begin{abstract}
The success of any plant is generally fostered by many factors that affect directly the production. The relevant ones are, low capital investment, low operating cost, and high production efficiency. Energy consumption is a key element that influences the operating cost factor. Indeed, the electrical power consumed by electrical motors in an LPG plant constitutes one of the major sources of energy consumption. Motorized systems' optimization can generate important energy saving, improving and energy efficiency for the following systems: compressed air system, ventilation system and pumping system. Variable frequency drive offers many advantages in centrifugal pumps' operation. It can improve process control, equipment reliability and cost savings.
\end{abstract}

In this paper, a study of energy saving opportunity in pumping systems using low affinity equations is presented. For this purpose, three factors have been measured: the flow rate, pressure and the electrical power drawn by the electric motor. Energy efficiency of the existing system consisting of the pump driven by the electrical motor has been calculated using on site measured data.

Keywords: Energy efficiency; Pump; Variable frequency drive; LPG

Nomenclature: LPG: Liquefied Petroleum Gas; HP: power; N: speed of rotation, revolutions/min; Q: flow rate, $\mathrm{m} 3 / \mathrm{hr}$; P: pressure, bar; $\eta$ : pump efficiency; SG: liquid density, Kg/m3; VFD: variable frequency drive; DCS: distributed control system; NPSH: Net Positive Suction Head; BEP: best efficiency point; MAD: millions of Algerian dinar

\section{Introduction}

Energy management in electrical motors and its applications is a major research area that allows significant energy saving in industrial plants. It is estimated that $20 \%$ of all electrical power is used to drive industrial pumps. According to a study driven by M. Pemberton [1], around $20 \%$ to $50 \%$ of the power consumed by electrical motors can be saved through variable speed operation. Using Variable Frequency Drive (VFD) in adjusting the pump speed has proven to be an efficient way to decrease the adjustment losses in pumping processes [2,3]. This can be a significant advantage for the Liquefied Petroleum Gas (LPG) industry, which uses many pumps and cooling fans in its production processes. Traditionally, pump flow rate is controlled by throttling valves or balancing valves on the discharge side of the pump. The benefit of speed adjustment is that efficiency of the pump usually drops much less compared to the throttling adjustment and, depending on system curve, less energy is wasted compared to increased head when producing reduces flow with throttling adjustment [4-6]. In many cases, variable speed pumping has been shown to be an effective way to reduce total pumping costs for systems that require a wide range of flow [7].

The pumps are often oversized in the initial design process allowing a safe margin during operations. However, this has a direct negative consequence on the capital cost. Indeed, oversizing causes more energy consumption and possible throttling losses when the workload is adjusted to the desired level [4]. Moreover, energy added inherently to the fluid is wasted at the control valve. The use of VFD can help to overcome this problem by downsizing the pumps. However with the throttle valve we cannot avoid the pressure losses resulting in high energy consumption.

Innovation in LPG industry has the objective of reducing cost and increasing competitiveness. Since energy consumption is a major contributor to costs, the emphasis on the technological fields has focused mainly on methods or devices to improve efficiency. In this paper we will study the integration of the variable frequency drive into an electric motor driving a pump. With a VFD, not only power saving can be achieved but also operational benefits. The work done in this paper is a theoretical study based on the measured data taken from the plant.

The pumping system studied in this paper is used in the separation section that is one of the three LPG process sections (Dehydration, separation, refrigeration). The heat conductor fluid used is the Torada - a kind of oil. This fluid is heated by a furnace, which in turn heats the bottom of the column by crossing a re-boiler. The objective of this part of the process is to separate the slight fraction of the propane from the heavy fraction of butane

\section{Description of the System}

The circuit of the heat conductor fluid is a closed loop; it holds a tank, a pump, a furnace and different applications (Figure 1).

The all pumping system with furnace are controlled by the distributed control system (DCS). To ensure a good quality operation of the process some instructions are implemented.

The pressure at the furnace inlet should be more than 6 bars to overcome the pressure drop in the furnace coil. In case where this instruction is not checked the DCS will switch off the furnace.

If no speed control is installed, the only way to achieve the desired flow rate is to artificially increase the resistance of the system by closing a valve. This higher pressure with more driving power than otherwise needed will result in throttling losses. On the other hand, a speed control will change the characteristic of the installed pump (Figure 2).

The process curve can be obtained from the knowledge of the piping

*Corresponding author: Salem Hebri, Research and Technology Division SONATRACH, BP 74-31230 SONATRACH Village N06, Aïn El Bia, Algeria, E-mail: salem.hebri@gmail.com

Received January 03, 2012; Accepted February 15, 2012; Published February 18,2012

Citation: Hebri S (2012) Variable Frequency Drive Importance in an LPG Plant: Case Study. J Elec Electron 1:101. doi:10.4172/2167-101X.1000101

Copyright: (c) 2012 Hebri S. This is an open-access article distributed under the terms of the Creative Commons Attribution License, which permits unrestricted use, distribution, and reproduction in any medium, provided the original author and source are credited. 


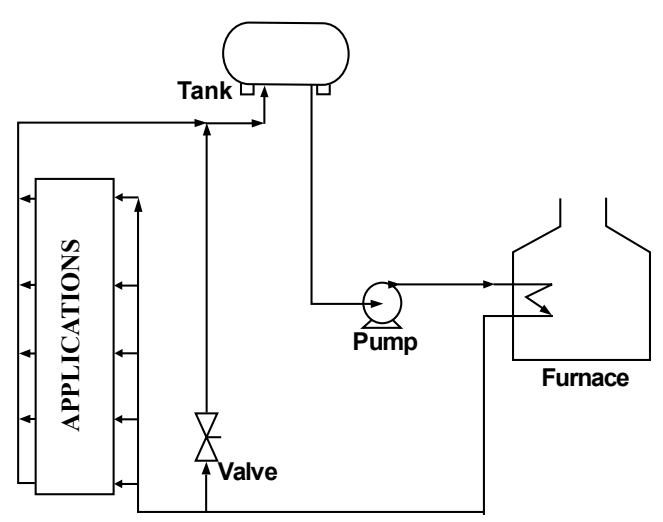

Figure 1: Hot oil pump system.

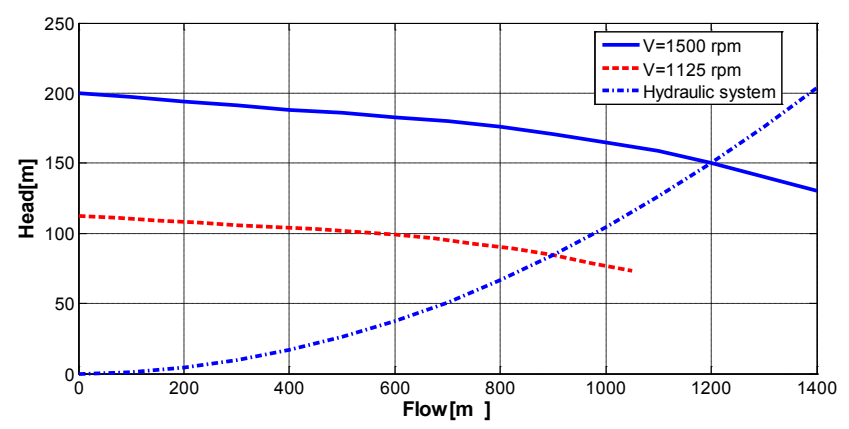

Figure 2: Pump/system characteristics.

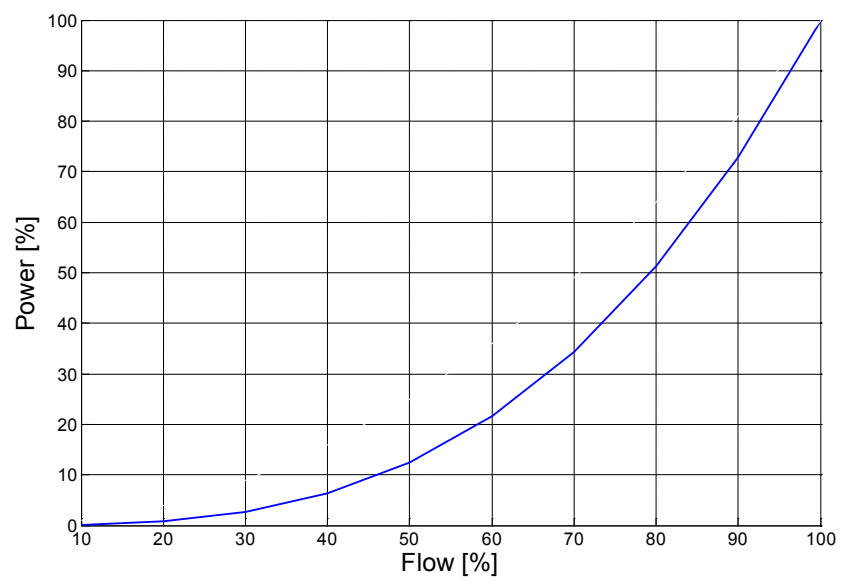

Figure 3: Relation between energy consumption and the flow using VFD in a system with no static head.

and the static head by simple laws of hydraulics, or it can be determined by test measurements. In general, the process curve shape is defined by equation (1)[8]:

$$
\mathrm{H}_{\text {process }}=\mathrm{H}_{\mathrm{st}}+\mathrm{kQ}^{2}
$$

Where $\mathrm{H}_{\mathrm{st}}$ is the static head of the process and $\mathrm{k}$ is the coefficient for the dynamic head (i.e., friction losses).
The oil reaches the furnace by a pump in a close loop circulation system, this means that the flow and pressure relationship pass through zero at the same time Figure 2, this also means that $\mathrm{H}_{\mathrm{st}}$ in the equation (1) is equal to zero.

The pump characteristic curve at the fixed speed is provided by the manufacturer.

In all processes, a variable speed drive eases the automatic startup procedure without the need for highly sophisticated control equipment. Reduced pump loading will increase bearing life of all pumps. Cavitation due to insufficient NPSH-values will be avoided.

As shown in Figure 2, with a speed at1125 rpm, the pressure at the desired flow rate is 8.45 bars; knowing that the pressure drop between the pump outlet and the furnace inlet is around 0.8 bars. According to these values, the instruction of the pressure at the furnace inlet is verified and our system will keep working.

\section{Calculating Energy Savings}

If the rotational speed of the pump differs from the nominal value, it affects the pump characteristics, which can be demonstrated by affinity equations:

$$
\begin{aligned}
& \frac{Q}{Q_{\text {nom }}}=\frac{N}{N_{\text {nom }}} \\
& \frac{P}{P_{\text {nom }}}=\left(\frac{N}{N_{\text {nom }}}\right)^{2} \\
& \frac{H P}{H P_{\text {nom }}}=\left(\frac{N}{N_{\text {nom }}}\right)^{3}
\end{aligned}
$$

Where $\mathrm{N}$ is the instantaneous rotational speed of the pump, and the subscript nom denotes the value at the nominal speed [9]. When the rotational speed and the power consumption of the pump are estimated by the motor model [10], QP and QH curves can be transformed into the instantaneous rotational speed, and the location of the operating point can be solved from the transformed characteristic curves as shown in (Figure 2).

The figure below (Figure 3), illustrates the importance of energy saving using the variable frequency drive by the cubed approximation.

The pump used is a centrifugal pump driven by a three-phase induction motor, (Table 1), shows the data sheet of the centrifugal pump at operating conditions.

The BHP may be read from the power curve or may be calculated using the formula below.

$$
B H P=\frac{\text { Flow } \times \text { Head } \times S G}{K \times \text { Efficiency }}
$$

Flow is in $\mathrm{m}^{3} / \mathrm{hr}$

Head is in meters

$\mathrm{SG}=0.8$ is the specific gravity

Efficiency is to a decimal point i.e. $62 \%$ becomes 0.62

$\mathrm{K}=368$ if the flow is in $\mathrm{m}^{3} / \mathrm{hr}$

\begin{tabular}{|l|l|}
\hline FLOW RATED & $1200 \mathrm{M}^{3} / \mathrm{HR}$ \\
\hline DIFF HEAD & $150 \mathrm{~m}$ \\
\hline EFFICIENCY & $62 \%$ \\
\hline RPM & 1490 \\
\hline SG & 0.88 \\
\hline BHP RATED & $695.8 \mathrm{~kW}$ \\
\hline
\end{tabular}

Table 1: The operating conditions data. 
The measured data (Figure 4), were taken on a period of one year, 8760 hours. The pump choosen for the study is used $70 \%$ of the time. For the remaining $30 \%$ of the time, another pump with the same characteristics is used. The flow rate provided by the pump is around $900 \mathrm{~m}^{3} / \mathrm{hr}$ (Figure 4 ), The natural operating point is at $1200 \mathrm{~m}^{3} / \mathrm{hr}$, this means that in this case the pump is operating $25 \%$ below the best efficiency point, resulting in low hydraulic efficiency.

To calculate the power consumption, we measured the current and we used the equation below.

$$
P=\sqrt{3} I V \operatorname{Cos} \phi
$$

I: current data

\section{V: supply voltage}

$\operatorname{Cos} \varphi: 0.85$

Using the equations above (6), the electrical consumption is around $530 \mathrm{kWh}$. The dashed curve (Figure 5), shows the variations of the electrical energy consumption along the year 2009.

However, the experience shows that in some cases the power needed to drive the pump is proportional to the motor speed squared and not the motor speed cubed. This is caused mainly by the real effects of the system

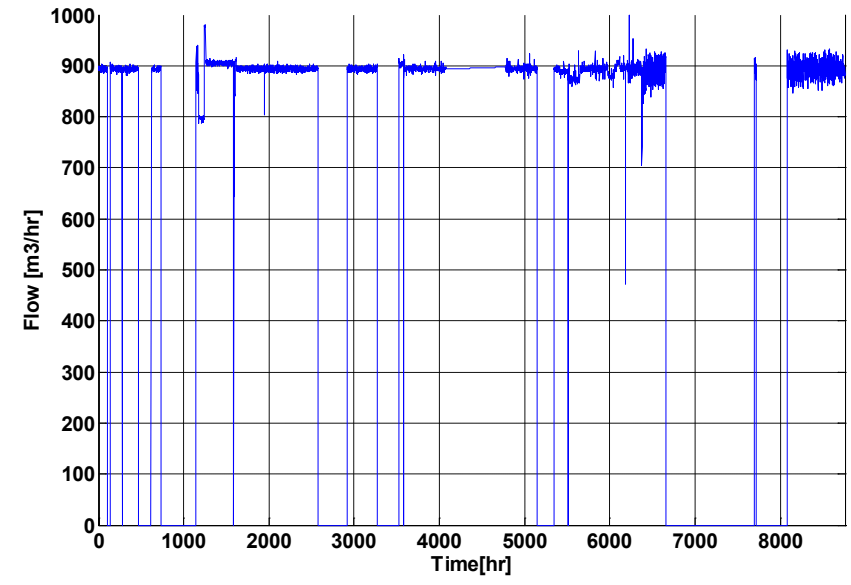

Figure 4: The measured flow rate during the year 2009.

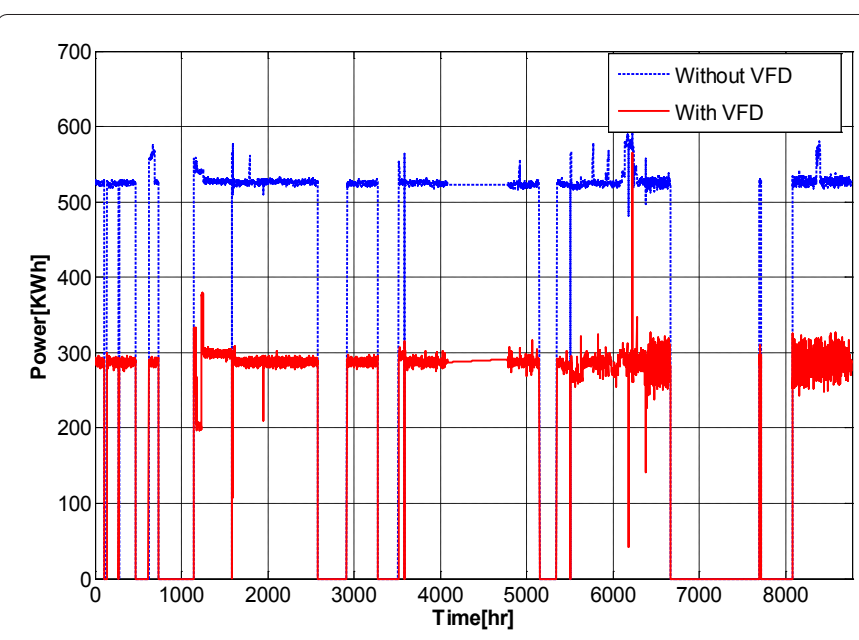

Figure 5: The electrical energy consumption during 2009; The dashed curve without the VFD, the solid curve with the VFD.

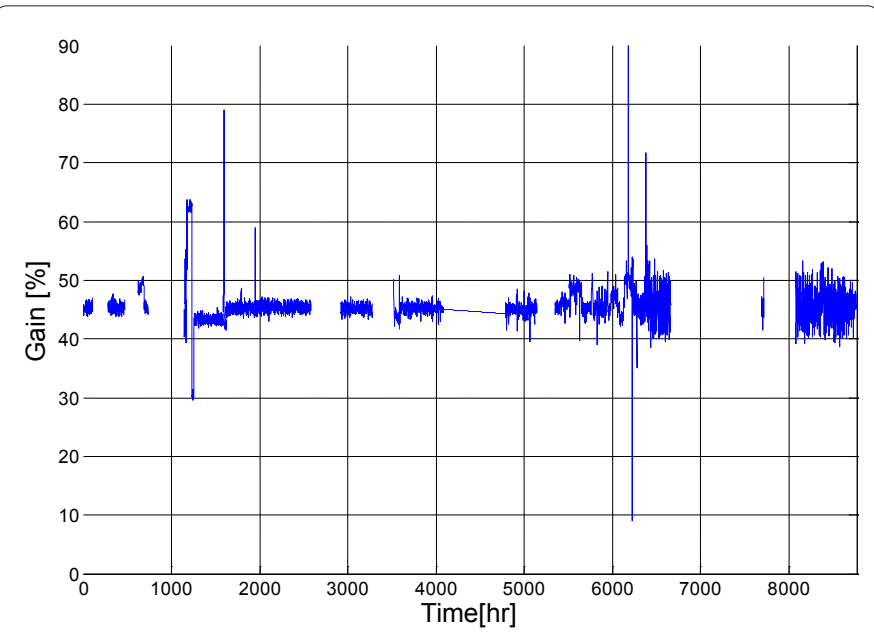

Figure 6: The estimation of energy saving during 2009.

as static head of the process or the friction losses [11]. In this case the static head is equal to zero (Figure 2), and the opportunity to save energy is more important.

To determine the electricity savings associated with using speed control, the BHP for the fixed-speed and the adjustable speed case must be determined for the various flows under consideration. For the fixed-speed case, it is a simple matter of using the pump manufacturer's flow versus horsepower curve (Figure 2) or measuring the power into the motor and factoring in motor efficiency. On the other hand, the calculation for the adjustable speed is done at the flow rate at which the pump is working.

Combining (2) and (3), results in

$$
\frac{P}{P_{\text {nom }}}=\left(\frac{Q}{Q_{\text {nom }}}\right.
$$

Using (7), results in

$$
\mathrm{H}=150(900 / 1200)^{2}=84 \mathrm{~m}(8)
$$

Combining (2) and (4) and solving

$\mathrm{HP}=695.8(900 / 1200)^{3}=293.5 \mathrm{kWh}(9)$

The $293.5 \mathrm{kWh}$ is a significant reduction from the $530 \mathrm{kWh}$ measured when the pump is working at fixed speed. The solid curve Fig.4 shows the variations of the electrical energy consumption when the pump is associated to a variable speed drive.

Referring to (Figure 2), the process curve indicates that $84 \mathrm{~m}$ of head is required to deliver $900 \mathrm{~m} 3 / \mathrm{hr}$. Driving the pump at $1125 \mathrm{rpm}$ can be enough to meet the process requirements. With this velocity, the pump can provide the flow rate needed in the process operation with the right pressure.

Looking at (Figure 5), the electrical energy consumed by this pump during the year data is about 3.15214 GWh. Referring to (Figure 6), in all the time when the pump is working, the energy saving is around $45 \%$ and can reach $50 \%$, what means that we can save around 1.41846 GWh. The mean energy price $(\mathrm{DA} / \mathrm{kWh})$ in Algeria is around $1.73 \mathrm{DA} / \mathrm{kWh}$, what allowed the company to save $2.36883 \mathrm{MAD}$. This pump is working only $70 \%$ of the time if we suppose that the second pump has the same characteristics, hence gain will be around 3.385 MAD in this part of the process. This estimation is done by considering the Algerian energy price. The saving amount can be more important if the international mean price is applied. 


\section{Conclusion}

Energy cost represents one the major production cost factors in the petroleum industry. Working on improving energy efficiency represents a crucial way to reduce costs and increase predictable earnings. VFD in pumping applications allows controlling efficiently the operating cost. Besides, it provides the user with an easy way to control the process. Reducing the pump speed with a VFD unit results in flow rate reduction and has a direct impact on the pump's energy consumption. In the present study, the electricity consumption with the VFD was about $293.5 \mathrm{kWh}$ instead of $530 \mathrm{KWh}$ without VFD for the same operating conditions. The interpretation of the figures presented in this paper shows that it is mandatory to control the speed of all the process pumps. Proven, no risk equipment is available. It has been shown that economic benefits can be gained, especially for a LPG plant where more than 100 rotating machines are used; the energy that can be saved is enormous.

\section{Acknowledgment}

The author gratefully acknowledges the contribution of engineers from the technical department (GP2Z-Gas Petroleum Plant 02) for their help in this study.

\section{References}

1. Mike Pemberton (2005) Variable speed pumping: myths and legends. World Pumps 2005: 22-24.
2. Pihala H, Kuoppamäki R, Hänninen S, Oy Indmeas Ab (2008) Sähkönsäästöpotentiaali energiatehokkailla sähkömoottorikäytöillä Suomen energiavaltaisessa teollisuudessa. VTT Research report.

3. Sulzer Centrifugal Pump Handbook (1998) ( $\left.2^{\text {nd }} e d n\right)$, Elsevier Limited, Oxford UK.

4. Volk M (2005) Pump Characteristics and Applications. (2ndedn), CRC Press, Taylor \& Francis Group.

5. $A B B$, Application guide No. 2: Using variable speed drives (VSDs) in pumping applications (2006) Helsinki: ABB Oy Drives.

6. Pump Life Cycle Costs A Guide to LCC Analysis for pumping systems (2001) Hydraulic Institute, Europump.

7. Europump and Hydraulic Institute (2004) Variable Speed Pumping - A Guide to Successful Applications. Elsevier Advanced Technology Oxford.

8. Tero A, Jussi T, Jero A, Juha V, Niina A, et al. (2010) Estimation of pump operational state with model based methods. Energy Conversion and Management. 51: 1319-1325.

9. Karassik IJ, McGuire T (1998) Centrifugal pumps. (2ndedn), New York Chapman \& Hall.

10. Nash J (1997) Direct torque control, induction motor vector control without an encoder. IEEE Trans Ind Appl 33: 333-341.

11. Natiral ressources Canada, Variable Frequency Drives - Energy Efficiency Reference Guide (2009) Ceati International. 